\title{
INDICADORES DE CLIMA ÉTICO NAS EMPRESAS
}

Maria Cecilia Coutinho de Arruda

Professora do Departamento de Mercadologia da EAESP/FGV, Coordenadora do Centro de Estudos de Ética nas Organizações (CENE) da EAESP/FGV e Presidente da Associação Latino-Americana de Ética, Negócios e Economia (ALENE).

E-mail:carruda@fgvsp.br

Frank Navran

Diretor de Consultoria em Ética do Ethics Resource Center (Washington/EUA).

\section{RESUMO}

Todo executivo se preocupa em conhecer a situação de sua empresa em relação ao mercado no que diz respeito à ética e, para isso, é preciso saber qual é o patamar ético das organizações brasileiras. A existência de um indicador para avaliar o grau de eticidade de uma empresa, a partir de seu clima ético, foi o alvo deste estudo, pioneiro no Brasil. O objetivo deste artigo é estimular os executivos a se preocuparem com a qualidade ética de sua organização, informando-lhes e colocando à sua disposição um trabalho que vem sendo desenvolvido desde 1998 pelo Centro de Estudos de Ética nas Organizações (CENE)/EAESP/FGV em parceria com o Ethics Resource Center, em Washington, DC, EUA. Serão apresentados os indicadores quanto à sua construção e aplicação ao setor industrial brasileiro.

\section{ABSTRACT}

Any businessperson is interested in knowing the position of his/her company in the market in what concerns ethics. For this purpose, it is imperative to identify the ethical level of Brazilian organizations. Based on the ethical climate of an organization, an indicator was created to evaluate a firm's degree of eticity, in a pioneer research project in Brazil. The objective of this study is to encourage the executive to pay attention to the ethical quality of his/her organization, providing information and offering a service that has been developed by the CENE (Center of Studies for Ethics in the Organizations)/EAESP/FGV in partnership with the Ethics Resource Center, in Washington, DC, USA, since 1998. The methodology for creating the indicators, as well as its application to the manufacturing industry, is presented in the article.

\section{PALAVRAS-CHAVE}

Indicadores de ética, indicadores de ética empresarial, ética empresarial no Brasil, clima ético nas organizações.

\section{KEY WORDS}

Indicators of ethics, business ethics indicators, business ethics in Brazil, organizational ethical climate. 


\section{INTRODUÇÃO}

Como estará uma determinada empresa em relação ao mercado, no que diz respeito à ética? Qual será o patamar ético das organizações brasileiras? Que instituições poderiam ser chamadas de éticas atualmente no Brasil? Existe um indicador do nível de ética de uma organização? Como avaliar o grau de eticidade de uma empresa a partir de seu clima? Essas indagações, entre tantas outras, vêm sendo alvo de estudos e pesquisas em muitos países. O objetivo deste artigo é estimular os executivos a se preocuparem com a qualidade ética de sua organização, informando-lhes e colocando à sua disposição um trabalho que vem sendo desenvolvido desde 1998 pelo Centro de Estudos de Ética nas Organizações (CENE)/EAESP/FGV em parceria com o Ethics Resource Center, em Washington, DC, EUA. Serão apresentados os indicadores quanto à sua construção e aplicação ao setor industrial brasileiro.

\section{ESTRUTURA DE MENSURAÇÃO DA ÉTICA EMPRESARIAL}

Muitos modelos têm sido propostos com o intuito de mensurar o nível ético de uma organização, e alguns devem ser citados. $\mathrm{Na}$ década de 70, por exemplo, Ackerman e Bauer já apresentavam uma matriz de auditoria social em que cada célula seria uma afirmação verbalizada, quantificada ao máximo, a respeito do quão seriamente a empresa considerava as conseqüências de suas ações (Ackerman e Bauer, 1976). Nas linhas estavam representados os stakeholders e, nas colunas, as principais atividades da empresa: produtos, produção, marketing, finanças, localização dos edifícios, $\mathrm{P} \& \mathrm{D}$, desenvolvimento de novos negócios, relações com o governo e programas especiais. Os autores notaram que existia uma limitação séria no estudo, pois este não previa que o papel da empresa fosse sendo claramente revisto à medida que o tempo passasse e as circunstâncias mudassem. No curto prazo, as organizações deixaram de responder com a mesma facilidade.

Em 1994, Zadek, da New Economics Foundation, idealizou um processo de auditoria social, em que definia, observava e registrava medidas do comportamento ético em uma organização, em relação aos seus objetivos e aos de seus stakeholders (Zadek, 1994). Seu principal interesse era publicar anualmente esses indicadores - mormente os de desempenho social - para que as empresas os utilizassem como benchmarking no esforço por melhorar suas práticas.

\section{A pessoa e a organização são mais eficientes quando há congruência entre os valores e as crenças a respeito de como o trabalho deve ser feito e as expectativas e exigências da organização em relação ao sucesso.}

Significando um passo à frente, formouse nos Estados Unidos o Council on Economic Priorities Accreditation Agency (CEPAA), que desenvolveu, em 1997, um padrão internacional, baseado em convenções sobre direitos humanos, para que as empresas cuidassem de questões como trabalho infantil, saúde e segurança, liberdade de associação, direito a negociação coletiva, discriminação, horas de trabalho e remuneração, inclusive salários mínimos. Trata-se do Social Accountability 8000 ou SA8000, logo acolhido por muitas organizações (CEPAA, 1997). O objetivo de estabelecer valores para benchmarking, com ênfase na informação aos stakeholders, ficou mais conhecido nas organizações como o fundamento dos programas de compliance, muito em voga nos Estados Unidos desde então. Da mesma forma que para os demais indicadores, especial dificuldade surgiu no momento de definir qualitativamente a responsabilidade social da empresa e o quanto esse conceito estava de fato absorvido, a ponto de se garantir uma informação real e útil. Não é fácil mensurar o retorno do investimento em caridade ou da contribuição de responsabilidade social.

A revista Fortune publica anualmente a Corporate Reputation Survey, com as empresas norte-americanas "mais admiradas". O ranking constitui-se de 300 empresas de 32 
setores, a partir da opinião de 8 mil executivos a respeito de alguns atributos subjetivos: qualidade do gerenciamento, qualidade dos produtos, capacidade de inovação, valor dos investimentos de longo prazo, saúde financeira, capacidade de atrair e manter pessoas de talento, responsabilidade com a comunidade e com o meio ambiente e bom uso dos ativos da empresa. Nota-se que a preocupação direta com os funcionários, ou o clima ético das empresas, também não é o ponto central da pesquisa.

\section{A ética está amplamente constituída de regras de sobrevivência, regras de comportamento associadas à profissão, regras de relacionamento que possibilitem harmonia na convivência social e assim por diante.}

\section{O MODELO DE NAVRAN}

De um modo geral, os modelos parecem ter-se prendido mais à responsabilidade social das empresas, ou seja, à satisfação dos seus stakeholders externos: acionistas e sociedade em geral. Numa análise crítica, talvez os indicadores tenham sido utilizados mais como um instrumento de marketing que possibilitasse avaliar a imagem que esses stakeholders fazem da instituição do que propriamente indicadores do nível ético das organizações. Nesse sentido, o trabalho de Navran pareceu ideal para o momento de desenvolvimento da Ética Empresarial no Brasil.

O princípio básico do modelo de Navran é o da congruência ou consistência: a pessoa, individualmente, e a organização são mais eficientes quando há congruência entre os valores e as crenças a respeito de como o trabalho deve ser feito e as expectativas e exigências da organização em relação ao sucesso. O conjunto de expectativas percebidas e exigidas é denominado clima ético e constitui objeto deste estudo.

Para ajudar a descrever a percepção dos funcionários a respeito do clima ético de uma organização, há cerca de 20 anos, Frank Navran desenvolveu e testou, embora não chegasse a publicar, um instrumento de mensuração do clima ético que possibilitasse:

- esclarecer os dirigentes de uma organização a respeito das suas equipes, de seus departamentos ou de outros grupos da empresa;

- levantar resultados de consistência ética dentro de dez dimensões do clima ético;

- identificar opções de resposta da empresa, na busca por melhor consistência ética (Quadro 1).

\section{INDICADORES DE CLIMA ÉTICO A} PARTIR DO MODELO DE NAVRAN

\section{Indicador 1: Sistemas formais}

Há muito tempo, os filósofos parecem estar de acordo com a idéia de que, para que o processo decisório seja eficaz, são necessárias regras. Do ponto de vista moral, esse pensamento procede, pois a ética está amplamente constituída de regras de sobrevivência, regras de comportamento associadas à profissão, regras de relacionamento que possibilitem harmonia na convivência social e assim por diante.

Tom Morris (1998, p. 152-156) entende que a ética é o cumprimento de regras. Sob essa perspectiva, a empresa que almeje ser ética deve divulgar declarações precisas definindo as regras e deve criar procedimentos de verificação para assegurar que todos na organização as estão cumprindo. Há muitas empresas que elaboram manuais de ética para seus funcionários e indicam representantes que garantem a ética ou a conformidade, supervisionando a conduta de todos os empregados. A experiência das organizações que utilizaram esse procedimento mostrou uma redução substancial do clima de incerteza, o que contribuiu sobremaneira para a consecução dos resultados em um clima construtivo.

Para Pérez López (1998), um sistema de controle pode determinar o que é preciso fazer numa posição, ou mesmo na empresa, para se alcançar os resultados esperados. Como conseqüência, serão atribuídos prêmios, castigos ou outras formas de resposta. Grande parte da literatura sobre organizações, particularmente empresas, concentra-se nos sistemas formais de controle, procurando definilos e estruturá-los em função dos problemas a 
serem resolvidos, como dispor os recursos, etc. No entanto, tradicionalmente, os sistemas formais apresentam limitações, cujas raízes se encontram na falta de uma definição adequada dos objetivos ou em indicadores insuficientes. Os incentivos para que as pessoas rendam mais, advindos dos sistemas formais, serão tão grandes ou maiores que os dos próprios sistemas formais. De um modo geral, os sistemas de controle formal levam as pessoas a limitar-se ao puro cumprimento das obrigações, a uma postura de apatia e indiferença. Por essa razão, as empresas necessitam da conduta espontânea. Se quiserem alcançar seus verdadeiros objetivos, e não apenas o mero cumprimento de umas normas, não poderão prescindir dela.

Hitt (1990) afirma que as funções gerenciais deveriam ser assumidas de acordo com um volume considerável de regras, independentemente das pessoas, já que o objetivo da burocracia é racionalizar a função de liderança. Isso pressupõe boa estrutura, normas e, acima de tudo, objetividade. A característica emocional da pessoa a exercer as funções gerenciais pode definir a maior ou a menor objetividade do processo. Por isso, cada gerente deve se esforçar especialmente para eliminar toda e qualquer subjetividade e sentimentalismo no desempenho de sua função.

Para Frank Navran, os sistemas formais da organização correspondem aos métodos, às políticas e aos procedimentos que claramente identificam qual é o negócio, quando, como, onde e por que ele se realiza. Quando os sistemas formais contêm um direcionamento ético claro, os funcionários têm uma compreensão correta das expectativas e exigências. Quando esses sistemas não são claros ou quando a mensagem ética varia entre os sistemas, os indivíduos buscam outro ponto de referência para uma orientação definitiva, uma dimensão tipicamente de liderança. Quando os sistemas não se referem à questão ética, a mensagem é que não existe um padrão ético. Isso deixa os funcionários totalmente dependentes de seus valores pessoais e do comportamento observável dos outros.

\section{Indicador 2: Mensuração}

De acordo com Nash (1993, p. 189), muitos dos sistemas mais comuns de incentivos, formas de comunicar os objetivos e a hierar- quia motivam o funcionário da organização. Por essa razão, convém examinar as repercussões de uma eventual egocêntrica satisfação, para reforçar o caráter objetivo da gerência, o foco na criação de valor, e não na ganância, o incentivo de opiniões divergentes para corrigir uma tendência ao interesse próprio e o desenvolvimento do raciocínio e das habilidades para o relacionamento.

\section{A empresa que almeje ser ética deve divulgar declarações precisas definindo as regras e deve criar procedimentos de verificação para assegurar que todos na organização as estão cumprindo.}

Melé (1997, p. 70) lembra que, ao trabalhar numa organização, tanto o gerente como os funcionários cooperam com outras ações realizadas por outras pessoas da empresa, de modo que essa cooperação também contribui para a moralidade dos atos com os quais coopera. Assim, as regras ou normas definidas podem evitar que haja cumplicidade por parte de todos os gerentes e funcionários, e um sistema de avaliação pode assegurar maior índice de eticidade da organização.

Para Navran, de todos os sistemas formais, as medidas são os meios mais críticos que a organização possui para comunicar às pessoas o que realmente é importante. As pessoas tendem a prestar mais atenção àquilo que é avaliado e medido, pois é justamente o mensurável que a organização traduz em recompensa. O uso de sistemas formais de avaliação depende de sistemas precisos de mensuração, além de uma clara definição de responsabilidades. Esses sistemas de mensuração devem ser percebidos como precisos e representativos do trabalho de uma pessoa ou de uma equipe. Isso significa que a integridade dos sistemas é tão importante quanto sua estrutura. Os sistemas formais contribuem para a congruência ética até o ponto em que se revelam confiáveis para representar as reais expectativas da organização. 


\section{Indicador 3: Liderança}

Hambrick et al. (1998) definem a liderança da maneira que julgaram mais aproveitável para a empresa:

- É suficiente modéstia para constantemente duvidar, estar aberto e escutar.

- É desempenho ao longo do tempo, não carisma.

- É responsabilidade, não privilégio.

- É um acreditar profundo e sincero nos valores e objetivos da organização e a capacidade de vivê-los, articulá-los e procurar com constância que outros os sigam também.

- É o desejo de provocar mudanças em tudo, exceto nos objetivos e valores básicos.

Para Hambrick et al., a liderança não pode se apoiar apenas nas pessoas que possuam essa qualidade, mas depende também dos seguidores e dos objetivos que todos almejam alcançar. Assim, são três os elementos que contribuem para a liderança eficaz. Ampliando a vertente ética, o autor apresenta novas perspectivas da liderança:

- É a integridade pessoal e instintivamente buscar conhecer e agir de forma certa.

- É a forte confiança no trabalho em equipe, no poder do relacionamento horizontal, não vertical, realçando os pontos fortes dos demais e não sabendo todas as respostas.

- É compreender que o sucesso pessoal só pode vir do trabalho do grupo e atribuir a todos o crédito que lhes é devido.

- É exigir subordinados fortes e sucessores potenciais, sem atropelá-los.

- É conquistar continuamente a confiança das pessoas.

- É o desejo de assumir riscos e a fortaleza de não temer o fracasso.

- É a contínua busca de educação: para o desenvolvimento próprio, a expansão e a renovação.

- É a contínua insatisfação com "as coisas como elas são", provocando mudanças para melhor.

- É a habilidade de ouvir e aceitar más notícias - e então ir para a frente -, usando a experiência como ferramenta de futuro desenvolvimento.

- É o talento de às vezes rejeitar o lógico e decidir em função do instinto e do coração.

- É criar a percepção e a realidade de que o líder é visível e tocável.
- É a concentração e a atenção para o que é importante.

- É conseguir informação confiável por meio de uma rede de fontes que permita a formação de juízos.

- É a rijeza e a disposição de usar o poder e a pressão, mas sempre depois de pensar bem e com cautela.

- É a habilidade de sentir-se confortável ao tratar da ambigüidade.

- É a confiança de que a qualidade verdadeira define todos os relacionamentos e que o sucesso advém necessariamente de uma qualidade existente.

- É um senso de otimismo que contagia e irradia, mesmo nos momentos mais difíceis.

- É possuir um senso de humor aberto e positivo, a habilidade de rir de si mesmo e dos imprevistos da vida.

Se a liderança depende das pessoas em torno do líder, Melé (1997, p. 106) lembra uma característica a ser por este desenvolvida, para que se alcancem os objetivos mais profundos das organizações. A solidariedade pode ser definida como a contribuição ao bem comum nas independências sociais, de acordo com a própria capacidade e as possibilidades reais.

Para Navran, a liderança é um fator crítico de sucesso para as organizações que se esforçam para aumentar a consistência ética. As ações e os comportamentos dos líderes pesam significativamente mais que suas palavras ou as políticas escritas. Quando as mensagens não são congruentes, os funcionários ficam ponderando qual delas deve ser considerada. A sinceridade dos líderes acima do supervisor imediato é posta em dúvida. As pessoas são forçadas a se apoiar nas opiniões de seus pares ou em suas próprias crenças para descrever os limites de um comportamento eticamente adequado. Então, têm que contrabalançar essas visões com aquilo que acreditam ser o que a organização realmente quer ou espera.

\section{Indicador 4: Negociação}

Uma das realidades difíceis de se medir e quantificar é o senso de união no local de trabalho. Ele estimula as pessoas a iniciarem seu trabalho pontualmente, a manterem o ritmo até o final do dia e evita o distanciamento entre elas. Os melhores líderes desenvolvem a unidade por meio da atenção consistente aos funcionários, fazendo-os participantes da 
"aventura" da organização. O respeito à singularidade leva à união entre todos, o que garante mais satisfação e qualidade no trabalho (Morris, 1998, p. 217). O sentido de unidade facilita acordos sempre que os planos devam ser mudados ou que as opiniões estejam divergindo entre si. É a base da negociação.

Para Navran, em toda a organização, os funcionários rotineiramente se engajam em uma negociação como estratégia para resolver um conflito. Negociam prazos, compromissos, alocação de recursos, atribuição de tarefas e exigências específicas. Quando a negociação com um cliente, um par ou um supervisor é percebida como uma situação de ganha-perde, o sistema de valores internos das pessoas ajuda a determinar os limites da negociação. A integração dos valores organizacionais à negociação ajuda a mudar o foco para resultados mutuamente benéficos. A negociação se torna um processo para desenvolver soluções ótimas, em vez de uma competição para determinar quem ganhará ou quem perderá.

\section{Indicador 5: Expectativas}

Hitt (1990) comenta que uma organização burocrática não pode dar lugar aos favores políticos. Conceder cargos a conhecidos ou parentes simplesmente porque são seus amigos está completamente em desacordo com os princípios básicos em que a empresa foi estabelecida. Todas as indicações deveriam se pautar em considerações objetivas das qualificações técnicas. Essa objetividade pode ser conseguida pela seleção de novos funcionários por meio de testes escritos, para evitar favoritismo, subjetividade e viés.

Para Navran, a organização tem suas exigências formais e informais para alcançar o sucesso. Essas são as expectativas que a organização tem para com seus empregados. Quanto mais explícitas e congruentes elas forem - não mutuamente exclusivas -, maior facilidade o empregado terá para avaliá-las, comparando-as com seus valores e suas crenças pessoais a respeito do que é certo ou errado. Os funcionários também comparam as expectativas com as suas próprias percepções a respeito de suas capacidades pessoais. Juntas, essas comparações formam a base de motivação dos empregados, para ir ao encontro das exigências da organização, visando a alcançar o sucesso.

\section{Indicador 6: Consistência}

Ferrell e Gardiner (1991) atribuem uma responsabilidade grande aos líderes no que diz respeito a fornecerem padrões de conduta ética para sua equipe. O reforço desse comportamento pode ser demonstrado pelo reconhecimento das atitudes corretas - e sua respectiva comunicação - e pela séria correção para os que se afastarem das normas éticas. A consistência se fortalece com a lealdade, o apoio e a confiança no líder que pessoalmente dá exemplos de conduta e que tem a humildade de retificar quando erra.

\section{As empresas necessitam da conduta espontânea. Se quiserem alcançar seus verdadeiros objetivos, e não apenas o mero cumprimento de umas normas, não poderão prescindir dela.}

Para Navran, a consistência ética ocorre quando todas as palavras e ações da organização levam as pessoas a concluir que o mesmo conjunto de valores éticos é válido a qualquer momento. Quando a organização é inconsistente, o funcionário não tem certeza do que deve pensar. Nesses casos, as circunstâncias individuais são usadas para definir o que é provavelmente exigido ou esperado. A falta de certeza, que leva a um comportamento autoprotetor por medo de fazer o que está errado, torna-se um fator primário de motivação. A atitude de evitar erros costuma reduzir o desempenho em cada categoria.

\section{Indicador 7: Chaves para o sucesso}

Se os funcionários trabalham para manter um clima amigável e harmonioso nas atividades de cada dia, com consistência, respeito, iniciativa e reconhecimento, a experiência de cada um favorece o estabelecimento de uma cultura empresarial ética, pois as pessoas são mais importantes que os produtos. A bondade é o único investimento que sempre recompensa, tanto em termos pessoais como em crescimento geral da organização (Morris, 1998, p. 136-137). 
Para Navran, há chaves para o sucesso em toda organização. Na maioria das vezes, tais chaves incluem o trabalho intenso, a automotivação e os resultados excelentes. No entanto, elas não se limitam a isso. Muitas organizações possuem suas próprias e específicas chaves de sucesso. Elas podem ser muito apropriadas: associação com um produto novo,

\section{As pessoas tendem a prestar mais atenção àquilo que é avaliado e medido, pois é justamente o mensurável que a organização traduz em recompensa.}

apoio a um mentor ou experiência em certas posições-chave. As questões éticas surgem quando essas chaves de sucesso específicas não são universalmente acessíveis, quando conflitam com a posição ética declarada pela organização ou com os valores pessoais amplamente aceitos dos funcionários. Quando isso ocorre, o sucesso é percebido como reservado a um pequeno grupo seleto, com um critério de seleção além do controle do indivíduo.

\section{Indicador 8: Serviço ao cliente}

Os funcionários que se sentem honradamente tratados tendem a transmitir a mesma honra e o mesmo respeito em seus contatos com clientes atuais e potenciais, fornecedores e consumidores. Quando existe mau trato, é comum que esse mal-estar também se reflita fora da empresa, na forma de lidar com os clientes e fornecedores e com outras pessoas com as quais os funcionários têm contato fora da empresa. Essa atitude pode dificultar a manutenção ou a abertura de negócios para a empresa. Assim, é pouco provável que, no longo prazo, um comprador venha a fazer negócios, ainda que o produto seja bom, se na empresa fornecedora as pessoas se manifestam de forma má ou descortês (Morris, 1998, p. 134).

Para Navran, quase toda organização reconhece a importância da satisfação do cliente. Para isso, também realiza treinamentos. Quando uma organização tem um padrão ético para seus clientes e outro para seus funcionários, problemas podem surgir. Os funcionários estão numa situação muito especial de verificar como a organização os trata e como ela espera ou exige que tratem os clientes. Se essas expectativas não forem congruentes ou coerentes, cria-se uma tensão na organização que pode resultar num mau atendimento aos clientes e em níveis crescentes de insatisfação dos funcionários. A maioria dos funcionários tem dificuldade de tratar os clientes sistematicamente melhor do que a organização os trata.

\section{Indicador 9: Comunicação}

Uma das principais razões para que exista a gerência é para que as regras sejam comunicadas e reforçadas numa empresa. A primeira tarefa gerencial deveria ser conhecer e aprender bem as normas da organização, estudando-as atenciosa e intensamente, pedindo esclarecimentos aos superiores e comprometendo-se a memorizar todo o manual de operações. A tarefa seguinte é comunicar essas regras aos seus subordinados e a qualquer empregado recentemente contratado. Quando surgem dúvidas específicas quanto à aplicação das regras, cabe ao gerente comunicar com a maior rapidez possível a interpretação correta e os critérios estabelecidos. Uma forma de reforçar as normas da empresa é comunicar, também, o seu eventual cumprimento, seu respectivo transgressor e a sua punição (Hitt, 1990, p. 148-149).

Para Navran, toda organização possui expectativas e exigências em relação a seus funcionários. Quando a empresa não consegue comunicar eficazmente aquilo que espera de seus empregados, reduz-se a probabilidade de que ela alcance os resultados esperados. As pessoas precisam de informações, de orientação e de reforço. Necessitam conhecer as posições, os padrões éticos da empresa e o que é considerado uma conduta correta dos funcionários num amplo espectro de situações com as quais poderão se defrontar. Além disso, precisam sentir-se coerentes com tais exigências. Por fim, os funcionários devem saber a quem se dirigir para obter respostas às suas preocupações éticas quando se defrontam com uma situação nova ou diferente.

\section{Indicador 10: Influência dos pares}

Morris (1998, p. 149) afirma que, se um 
grupo não adotar um comportamento ético, cada funcionário sofrerá forte pressão para se comportar da mesma forma. No local de trabalho, se as pessoas se acostumarem a aparar as arestas, a adaptar a verdade, a agir por mero interesse pessoal, significando atuar de forma não ética, e se seus pares tenderem a negligenciar o que realmente é verdadeiro nas pessoas, cada funcionário se sentirá pressionado a ter a mesma conduta que os colegas. A dificuldade de remar contra a correnteza não pode ser duradoura. É preciso fazer todo o possível para minimizar associações de cada funcionário com pessoas de má índole, de mau caráter ou de má vontade, seguindo o conselho de muitos grandes pensadores.

Para Navran, a influência dos colegas existe em quase todos os negócios, indústrias e profissões. As pessoas contam com seus colegas para direção, validação e reforço. Quando a organização falha em comunicar adequadamente seus padrões éticos e suas expectativas, os funcionários compensarão essa falha aumentando sua confiança no apoio dado pelos colegas. A organização pode influenciar o apoio dos colegas se, efetivamente, utilizar os colegas como parte do sistema informal de comunicação e educação. A empresa pode encorajar e incentivar os líderes informais, cujas posições e padrões éticos apóiam as metas desejadas da organização. A influência dos colegas pode se tornar uma parte do sistema de consistência ética como um todo.

\section{Indicador 11: Consciência ética}

Esse indicador de clima ético não está definido no Modelo de Navran. Como fruto do trabalho em conjunto do CENE/EAESP/FGV e de Frank Navran, ele foi criado no Brasil para avaliar questões mais características da região. $\mathrm{O}$ aspecto político em grande número de empresas brasileiras pode prejudicar o profissionalismo de uma equipe e implicar prejuízos para a organização. Na empresa, às vezes, as relações pessoais ou a influência política são muito mais valorizadas que o preparo técnico-profissional dos funcionários. Na relação chefe-subordinado, o uso da autoridade pode inclusive levar ao aparecimento de freqüentes casos de assédio sexual. Outro desvio que por vezes pode ocorrer é o de serem encobertas receitas da empresa, para não cumprir obrigações fiscais. Da mesma forma, o suborno acaba sendo entendido como um mal necessário, usado para garantir a competitividade dessa empresa. Por se tornar usual, o pagamento de suborno, propinas, presentes, etc. acaba não sendo considerado uma falta de ética dessa empresa.

Um gerente pode se sentir constrangido diante de situações que demonstram embotamento da consciência pessoal de alguém na empresa. Sua habilidade administrativa é testada na forma de processar e comunicar de forma acurada as informações. Se a imagem da organização é de invulnerabilidade e onisciência, pode resultar humilhante admitir o fracasso diante de outros, informando-lhes o erro cometido. Quanto mais baixo o nível hierárquico do gerente, maior será sua tendência a esconder as más notícias ou dúvidas a respeito de uma questão, por medo de ficar claro o seu erro (Nash, 1993, p. 176).

Quadro 1 - Indicadores e medidas de clima ético

\begin{tabular}{|c|c|}
\hline INDICADORES & MEDIDAS \\
\hline 1. Sistemas formais & $\begin{array}{l}\text { Regras e manuais? } \\
\text { Sistemas de controle? }\end{array}$ \\
\hline 2. Mensuração & Sistemas de avaliação? \\
\hline 3. Liderança & Políticas escritas e mensagens? \\
\hline 4. Negociação & Acordos? \\
\hline 5. Expectativas & Sistemas de seleção, promoção e correção? \\
\hline 6. Consistência & Palavras e ações da organização? \\
\hline 7. Chaves para o sucesso & $\begin{array}{l}\text { Lançamento de produto? } \\
\text { Auxílio a um mentor? } \\
\text { Experiência em posições-chave? }\end{array}$ \\
\hline 8. Serviço ao cliente & $\begin{array}{l}\text { Contato com clientes? } \\
\text { Manifestações de cortesia? } \\
\text { Treinamentos? }\end{array}$ \\
\hline 9. Comunicação & $\begin{array}{l}\text { Comunicação de regras? } \\
\text { Informação, orientação e reforço? } \\
\text { Esclarecimento de dúvidas? } \\
\text { Rapidez, precisão e punição em relação } \\
\text { ao cumprimento das normas? }\end{array}$ \\
\hline 10. Influência dos pares & $\begin{array}{l}\text { Sistema informal de comunicação e } \\
\text { educação? } \\
\text { Apoio dado aos colegas? } \\
\text { Apoio recebido dos colegas? }\end{array}$ \\
\hline 11. Consciência ética & $\begin{array}{l}\text { Relações pessoais? } \\
\text { Assédio sexual? } \\
\text { Uso dos ativos da empresa? } \\
\text { Pagamentos facilitadores? }\end{array}$ \\
\hline
\end{tabular}




\section{APLICAÇÃO DOS INDICADORES \\ DE CLIMA ÉTICO NA \\ INDÚSTRIA BRASILEIRA}

A construção dos indicadores de clima ético será realizada sempre a partir de um grupo de empresas que permanecem no painel durante dois anos. Assim, a informação coletada em 1998 está sendo atualizada em 2000, e a empresa segue participando do painel com os novos dados até 2002. A cada levantamento, a organização participante recebe seus novos indicadores, o que lhe permite desenvolver ações corretivas, reforçar as que promoveram melhorias no clima ético e realizar uma análise de benchmarking, comparando seus resultados com os do painel como um todo, uma vez que não se fornecem dados individualizados das demais empresas senão à própria interessada. Nesse sentido, poderão entrar e sair empresas a qualquer tempo, e os indicadores mostrarão a situação atual do painel.

Não é objetivo do CENE/EAESP/FGV divulgar um ranking por setor, pois as empresas brasileiras estão iniciando, de um modo geral, seus programas de ética. A intenção é incentivá-las a conseguir uma elevação do clima ético a partir dos valores, e não pela concorrência que um ranking possa suscitar.

Os dados dos indicadores que estão sendo divulgados agora pela primeira vez foram coletados em 20 indústrias manufatureiras no Brasil (Quadro 2). Solicitou-se que cada empresa participante enviasse no mínimo 50 questionários respondidos, ficando a critério da empresa a escolha dos respondentes, em termos de composição interna, posições hie-

Quadro 2 - Empresas participantes do painel de indicadores de clima ético (31.12.1997 a 31.12.1999)

\begin{tabular}{l|l}
\hline Alpargatas & Esso \\
\hline Armco & Hewlett-Packard \\
\hline Arteb & Maxilife-Nutrimental \\
\hline Blindex & Nitroquímica \\
\hline Cummins & Olivetti \\
\hline Dow Química & Siemens \\
\hline Eli Lilly & Union Carbide \\
\hline Ellus & Xerox \\
\hline Emerson & OPP Petroquímica \\
\hline Ericsson & YKK
\end{tabular}

rárquicas e funções, filiais, idade, sexo, escolaridade, etc.

A base da coleta de dados foi o questionário do Modelo de Navran, adaptado pela necessidade percebida. Foi incluído o tema da corrupção dentro do indicador "Consciência ética", enquanto outros de menor importância para o Brasil foram retirados. A confidencialidade foi sempre resguardada no processo de tabulação, cálculos e divulgação, por um compromisso do CENE/EAESP/FGV assumido com cada empresa e com cada respondente. No questionário, as assertivas referentes a cada indicador eram expressas em termos de concordância, e o respondente marcava sua opinião numa escala de 1 a 7 . Para fins de análise, os resultados em torno dos pontos de 1 a 3 foram considerados inaceitáveis (baixa concordância), 4 e 5 foram caracterizados como médios e 6 e 7 significaram excelência (alta concordância) em termos de clima ético da organização. Cada um dos 11 indicadores de uma empresa representa a média dos valores apontados pelos respondentes para as respectivas assertivas. Os indicadores setoriais representam a média das médias das empresas participantes do painel, para cada indicador (Tabela 1).

Nesta versão inicial, os indicadores do CENE/EAESP/FGV referem-se ao setor industrial. Durante o ano 2000, ampliando o trabalho, estão sendo desenvolvidos os mesmos indicadores para outros dois setores: serviços e empresas estatais, de modo que todas as organizações interessadas possam participar do painel gerador dos indicadores de clima ético ${ }^{1}$.

Das análises estatísticas, algumas poucas considerações caberiam ao final da apresentação dos indicadores. A falta de honestidade é aparentemente ensinada pelas autoridades da empresa. Quando falta ética nesse aspecto, a pressão dos colegas e subordinados sacrifica os padrões éticos em favor de resultados somente financeiros. A idéia de sobrevivência da organização parece ser a razão de muitas atitudes antiéticas. Infelizmente, existem motivos que são contrários às metas e aos padrões éticos da empresa. Quando os líderes são vistos como pessoas que "se acomodam ao sistema", sem a preocupação de influenciálo positivamente, a organização está deixando que o seu clima ético sofra. 
Tabela 1 - Indicadores de clima ético das empresas participantes do painel (31.03.2000, apresentação das empresas em ordem aleatória)

\begin{tabular}{|c|c|c|c|c|c|c|c|c|c|c|c|c|}
\hline \multirow[b]{3}{*}{ Empresas } & \multicolumn{12}{|c|}{ INDICADORES } \\
\hline & 1 & 2 & 3 & 4 & 5 & 6 & 7 & 8 & 9 & 10 & 11 & MÉDIA \\
\hline & 4,6 & 4,8 & 4,8 & 5,2 & 5,0 & 5,2 & 5,1 & 5,5 & 5,2 & 4,9 & 5,0 & 5,0 \\
\hline 1 & 5,3 & 5,3 & 5,3 & 5,6 & 5,7 & 5,6 & 6,0 & 6,2 & 5,5 & 5,6 & 5,3 & 5,6 \\
\hline 2 & 4,6 & 4,5 & 4,6 & 5,2 & 4,9 & 5,1 & 4,9 & 5,5 & 5,4 & 4,7 & 5,0 & 4,9 \\
\hline 3 & 5,1 & 5,3 & 4,8 & 5,4 & 5,2 & 5,3 & 5,2 & 5,7 & 5,7 & 5,3 & 5,0 & 5,3 \\
\hline 4 & 4,4 & 4,7 & 4,9 & 5,5 & 5,2 & 5,3 & 5,5 & 5,7 & 5,2 & 5,1 & 5,2 & 5,2 \\
\hline 5 & 4,5 & 4,4 & 4,6 & 5,1 & 4,7 & 4,9 & 4,9 & 5,2 & 4,7 & 4,8 & 4,8 & 4,8 \\
\hline 6 & 4,0 & 4,4 & 4,5 & 5,0 & 4,9 & 4,9 & 5,0 & 5,5 & 4,7 & 4,6 & 4,9 & 4,8 \\
\hline 7 & 3,4 & 3,3 & 3,6 & 3,8 & 3,4 & 3,5 & 3,6 & 4,5 & 3,4 & 3,8 & 4,9 & 3,7 \\
\hline 8 & 4,8 & 5,0 & 4,9 & 5,3 & 4,9 & 5,2 & 5,3 & 5,5 & 5,3 & 5,0 & 4,7 & 5,1 \\
\hline 9 & 4,2 & 4,1 & 4,0 & 4,6 & 4,6 & 4,2 & 4,8 & 5,2 & 4,7 & 4,8 & 4,4 & 4,5 \\
\hline 10 & 5,4 & 5,5 & 5,4 & 5,7 & 5,5 & 5,9 & 5,6 & 6,1 & 6,0 & 5,6 & 5,6 & 5,7 \\
\hline 11 & 4,8 & 4,9 & 4,9 & 5,6 & 5,2 & 5,5 & 5,3 & 5,5 & 5,3 & 4,8 & 5,3 & 5,2 \\
\hline 12 & 5,4 & 5,5 & 5,2 & 5,8 & 5,6 & 5,8 & 5,7 & 6,0 & 6,0 & 5,4 & 5,4 & 5,6 \\
\hline 13 & 4,1 & 4,4 & 4,3 & 4,7 & 4,7 & 4,5 & 4,9 & 5,5 & 4,7 & 4,6 & 4,5 & 4,6 \\
\hline 14 & 5,8 & 5,8 & 5,5 & 5,9 & 5,6 & 6,1 & 5,8 & 6,3 & 6,1 & 5,6 & 5,4 & 5,8 \\
\hline 15 & 4,2 & 4,1 & 4,4 & 4,6 & 4,6 & 4,3 & 4,7 & 5,0 & 4,6 & 4,7 & 4,4 & 4,5 \\
\hline 16 & 5,4 & 5,3 & 5,2 & 5,8 & 5,7 & 5,9 & 5,8 & 6,0 & 5,9 & 5,4 & 5,7 & 5,6 \\
\hline 17 & 4,5 & 4,4 & 5,0 & 5,4 & 5,2 & 5,2 & 5,4 & 5,6 & 5,3 & 5,0 & 5,1 & 5,1 \\
\hline 18 & 4,4 & 4,7 & 4,7 & 5,3 & 5,1 & 5,6 & 5,4 & 5,6 & 5,1 & 5,1 & 5,4 & 5,1 \\
\hline 19 & 3,4 & 3,8 & 3,8 & 4,6 & 4,4 & 4,5 & 4,4 & 4,2 & 3,6 & 3,6 & 4,6 & 4,1 \\
\hline 20 & 5,2 & 6,0 & 5,0 & 5,9 & 4,7 & 6,0 & 4,4 & 5,4 & 5,9 & 4,4 & 5,4 & 5,3 \\
\hline
\end{tabular}

REFERÊNCIAS BIBLIOGRÁFICAS

ACKERMAN, Robert, BAUER, Raymond. Corporate social responsiveness. Reston/Virginia : Reston Publishing/PrenticeHall, 1976. p.15.

CEPAA framework. New York, NY : CEP, 1997.

FERRELL, O. C., GARDINER, Gareth. In pursuit of ethics: tough choices in the world of work. Springfield, IL : Smith Collins, 1991. p. 91.

HAMBRICK, Donald C., NADLER, David A., TUSHMAN, Michael L. Navigating change. Boston, MA : Harvard Business School Press, 1998. p. 34-37.
HITT, William D. Ethics and leadership: putting theory into practice. Columbus, $\mathrm{OH}$ : Battelle, 1990. p.149.

MELÉ, Domènec. Ética en la dirección de empresas. Barcelona, España : IESE, 1997.

MORRIS, Tom. A nova alma do negócio: como a filosofia pode melhorar a produtividade de sua empresa. Rio de Janeiro : Campus, 1998.
NASH, Laura. Ética nas empresas: boas intenções à parte. São Paulo : Makron Books, 1993.

PÉREZ LÓPEZ, Juan Antonio. Liderazgo y ética en la dirección de empresas: la nueva empresa del siglo XXI. Bilbao, España : Deusto, 1998. p. 52-54.

ZADEK, Simon. Trading ethics: auditing the market. Journal of Economic Issues, v. xxviii, n. 2, June 1994.

\section{NOTA}

1. Para participar do painel, os responsáveis pelas empresas podem contactar o CENE/EAESP/FGV: 